\title{
Temperature, handling, micturition, and the survival of early weaned rats
}

\author{
GAYLON L. OSWALT \\ Developmental Psychobiology Laboratory, Nebraska Psychiatric Institute, \\ University of Nebraska College of Medicine, Omaha, Nebraska 68105 \\ and \\ MANFERD D. KOCH \\ University of Nebraska at Lincoln, Lincoln, Nebraska 68508
}

\begin{abstract}
Previous investigations reported that providing nonlactating maternally behaving adult females to infant rats weaned at 13 days of age substantially reduces the mortality rate of such weanlings. In experiments undertaken to isolate the maternal variable(s) promoting survival of early weaned rats we found that periodically inducing micturition or stimulation by handling did not alter viability. Thirteen-day-old weanlings did survive if provided with a source of heat, but did not survive at normal room temperature. It appears that the role of the nonlactating mother in the early weaning studies, at least in promoting survival, may simply be that of maintaining adequate body temperatures.
\end{abstract}

Normal or spontaneous weaning of young rats is a gradual process that occurs between 14 and 28 days of age (Krecek, 1971). Growing evidence indicates that experimentally induced early and suden separation of rat pups from their mother results in a number of lasting physiological and behavioral effects, either from social and/or nutritional factors. Thus, Nováková (1966a, b, 1970) found that early weaning impaired subsequent acquisition of classical conditioning but that either a high-fat diet or returning the mother to the litter after cauterizing her nipples to prevent lactation reduced the learning deficit. When pups were provided with both a high-fat diet and nonlactating mother, the effects of early weaning on learning were completely blocked.

Plaut and Davis (1972) found that the presence of a nonlactating rat "aunt" or a cauterized mother attenuated cerebral threonine deficits in early weaned animals but did not prevent decreases in body weight, brain weight, and/or cerebral aspartic acid in rats weaned at 15 days. When weaning was forced at an earlier age, 13 days, rat aunts were able to increase dramatically the proportion of animals surviving until 21 days (80\% vs. $10 \%)$. Plaut and Davis suggested that these latter findings might be attributed to the influence that an adult rat can have on directing the eating behavior of infants (Galef, 1971). However, Krecek (1971) in reporting a difference in the viability of 14-day-old vs. 16-day-old early weaned rats, offered an alternative explanation: deaths due to

The research was supported by Research Grant No. MH-17377-04 from the National Institute of Mental Health and Research Training Grant No.5 T01 HD-00122 from the National Institute of Child Health and Human Development.

We thank G. W. Meier and R. W. LoPresti for their comments on an earlier draft of this paper.

Reprints: Gaylon L. Uswalt, now at Department of Psychology, University of Nebraska at Omaha, Omaha, Nebraska 68101. weaning at 14 days resulted from "disruption of bladder function" due to the immaturity of the micturation response.

In attempting to isolate the aspect(s) or maternal deprivation responsible for the high mortality of rat pups weaned at 13 days, we conducted several initial experiments which will be briefly mentioned before describing the last and most critical study. The first two experiments were conducted to determine whether periodic elicitation of micturition by stimulation of the genitalia or periodic tactual stimulation by handling would enhance survival of early weaned rats. Surprisingly, virtually all of the 13-day-old weanlings in these studies survived regardless of experimental assignment.

Because methodological details differed between our first two studies and those of previous investigators, a third study, more closely matching the methodology of Plaut and Davis (1972), was conducted in an attempt to replicate previous findings and to reexamine the micturition and handling variables. Offspring of 13 Sprague-Dawley rats were weaned at 12 or 13 days of age and: (a) provided with a nonlactating (thelectomized) foster mother, (b) given stimulation for micturition four times a day, (c) handled four times a day, (d) left undisturbed. Survival rates were: $0 / 24$ of the subjects in the stimulation-for-micturition group, $3 / 24$ in the handled group, $4 / 24$ in the undisturbed group and 12/24 in the telectomized mother group. Whereas the presence of nonlactating foster mother promoted survival, experimentally induced micturition or periodic handling did not.

Contrary to the first and second experiments, in which high infant mortality was not found, the skin temperature of the handled pups in the third experiment was noticeably cool for several days after weaning. The 
first two experiments had been conducted in a laboratory that was involved with hand-rearing neonatal rats and high room temperatures $\left(28^{\circ} \mathrm{C} \pm 2^{\circ} \mathrm{C}\right)$ were habitually maintained. The third experiment was conducted in a different laboratory in which the room temperature was both lower and more varied $\left(23.5^{\circ} \mathrm{C} \pm 3.5^{\circ} \mathrm{C}\right)$. However, this room housed a healthy colony of rats and served successfully as a maternity area for normally reared rat litters. Several litters of normally mothered rats were being reared in the same room at the time of the third experiment and none showed any overt detrimental effects from these temperature conditions.

Taken together, our initial studies suggested that rat pups weaned at 13 days of age may not be able to survive normal room temperatures without the warmth provided by a maternally behaving adult. [Adolph (1957) placed the completion of maturation of thermoregulation in the rat at about 17.18 days of age.] Neither Plaut and Davis (1972) nor Krecek (1971) specified the ambient temperatures at which their animals were weaned. The following experiment compared rats weaned at 13 days in normal room temperature to those provided with an extra source of heat.

\section{METHOD}

Six litters from primiparous Sprague-Dawley (Sasco, Inc., Omaha, Nebraska) mothers (Rattus Norvegicus) were weaned at 13 days of age. At weaning, littermates were weighed, sexed, matched as closely as pcssible into pairs and the pairs were randomly split into heated and unheated groups. All weanlings were maintained in plastic cages with a bedding of ground corncobs. Each cage contained 4-6 pups. Pups in the unheated condition were maintained at a closely monitored room temperature of $22^{\circ} \mathrm{C} \pm 1^{\circ} \mathrm{C}$. Pups in the heated condition were maintained at the same room temperature but with heating pads under the plastic cages so that the temperature of the nest bedding remained at $30^{\circ} \mathrm{C} \pm 1^{\circ} \mathrm{C}$. Water and pellets of chow were freely available as was wet mash until 19 days of age. Subjects from three of the litters were also given trays of condensed cow's milk diluted with equal parts of water twice daily until the 19 th day of age.

\section{RESULTS}

All subjects were observed to have begun eating wet mash within $24 \mathrm{~h}$ of weaning. Body temperature of the pups in the unheated cages were noticeably cooler than those in the heated cages within $24 \mathrm{~h}$ of weaning. By the 16 th day of age most unheated pups had stopped eating and appeared lethargic. By 17 days of age, the limbs of the unheated pups appeared rigid and these pups walked in a stiff-legged manner. Between 18 and 20 days of age, all 25 pups in the unheated cages died. All of the 25 heated littermates survived.

\section{DISCUSSION}

One of the most dramatic examples of the effects of "maternal deprivation" has been the demonstration that maternally behaving, but nonlactating, adults can prevent the death of rat pups weaned at 13 days. Because these adults were nonlactating, their influence has been presumed to be social, as opposed to nutritional, in nature (Plaut \& Davis, 1972). In the present experiments, neither stimulation for elimination nor adult guidance to the location of food was necessary for the viability of 13-day-old weanlings.

The present findings strongly suggest that the role of the nonlactating maternal adult in promoting survival of 13-day-old weanlings can be accounted for on the basis of the maternal animal's ability to maintain adequate body temperatures. Rat pups weaned after 13 days of age, while surviving, may still show deleterious effects from exposure to normal room temperatures. Changes in neurochemistry or subsequent behavior of rats weaned before 17.18 days and whose body temperature is allowed to decrease may be most parsiomoniously explained in terms of thermal influences on the developing organism. Future studies of the effects of early weaning must examine the temperature variable more closely.

\section{REFERENCES}

Adolph, E. F. Ontogeny of physiological regulation in the rat. Quarterly Review of Biology, 1957, 31, 89-137.

Galef, B. G. Social effects in the weaning of domestic rat pups. Journal of Comparative and Physiological Psychology, 1971. 75, 358-382.

Krecek, J. Critical periods and postnatal endocrine development. In E. Tobach, L. R. Aronson, and E. Shaw (Eds.), The biopsychology of Development. New York: Academic, 1971. P. 233-248.

Nováková, V. Role of the mother during the suckling period of newborn rats on subsequent adult learning. Physiology and Behavior, 1966a, 1, 219-221.

Nováková, V. Weaning of young rats: Effects of time on behavior. Science, $1966 \mathrm{~b}, 151,475-476$.

Novák ová, V. Premature weaning of the rat: Its effect on the higher nervous activity and on the chemical pattern of neurons. In S. Kazda and V. H. Denenberg (Eds.), The post-natal development of phenotypes. Prague: Academic, 1970. P. 337-347.

Plaut, S. M., \& Davis, J. M. Effects of mother litter separation cn survival, growth and brain amino acid levels. Physiology and Behavior, 1972, 8, 43-51.

Received for publication August 13, 1974; accepted October 18, 1974.) 